\title{
Relative soil moisture in China's farmland
}

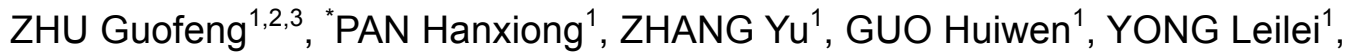 \\ WAN Qiaozhuo ${ }^{1}$, MA Huiying ${ }^{1}$, LI Sen ${ }^{4}$
}

1. College of Geography and Environmental Science, Northwest Normal University, Lanzhou 730070, China;

2. State Key Laboratory of Cryospheric Sciences, Northwest Institute of Eco-Environment and Resources, Chinese Academy of Sciences, Lanzhou 730000, China;

3. Gansu Engineering Research Center of Land Utilization and Comprehension Consolidation, Lanzhou 730070, China;

4. State Key Laboratory of Information Engineering in Surveying, Mapping and Remote Sensing, Wuhan University, Wuhan 430079, China

\begin{abstract}
Based on the data of relative soil moisture in 653 agricultural meteorological stations during the period of 1993-2013 in China, the characteristics and regularity of spatial and temporal variation of relative soil moisture in China's farmland were analyzed and discussed using geostatistical methods. The results showed that the relative soil moisture of China's farmland has shown a fluctuant increasing trend since 1993. The relative soil moisture of China's farmland is more than $60 \%$ in general, its distribution area has been expanded northward and westward with the summer monsoon since mid-April and began to shrink eastward and southward in late October. The value of relative soil moisture increases with the increase of soil depth. On an interannual scale, the relative soil moisture of farmland increased fastest in summer and autumn, and its variation range decreased with the increase of soil depth. The relative soil moisture was positively correlated with precipitation, and negatively correlated with potential evaporation and temperature. The correlation between relative soil moisture and various meteorological factors weakened as soil depth increased. The meteorological factors have a great influence on relative soil moisture of dry land in spring, summer and autumn and they also have a greater impact on relative soil moisture of paddy fields in winter.
\end{abstract}

Keywords: relative soil moisture; farmland; kriging interpolation; correlation analysis; spatial and temporal variation

Received: 2018-09-19 Accepted: 2018-11-22

Foundation: National Natural Science Foundation of China, No.41661005, No.41867030; Chinese Postdoctoral Science Foundation, No.2016T90961; National Natural Science Foundation Innovation Research Group Science Foundation of China, No.41421061; Autonomous Project of State Key Laboratory of Cryosphere Sciences, No.SKLCS-ZZ-2017; Remote Sensing Monitoring Special Project of Rotation and Fallow System in Pilot Regions under Ministry of Agriculture and Rural Affairs of the People's Republic of China, No.SCZG2017-ZB-2187/1-HT

Author: Zhu Guofeng (1983-), PhD and Associate Professor, specialized in hydrology and water resources.

E-mail: gfzhu@1zb.ac.cn

"Corresponding author: Pan Hanxiong (1993-), Master Student, specialized in hydrology and water resources research. E-mail: panhxnwnu@163.com 


\section{Introduction}

Soil supplies the water, nutrients, air and heat for the normal growth and development of crops. Its physical and chemical properties are easily affected by climate change (Zhu et al., 2010). In the field of agricultural monitoring, soil moisture is a comprehensive reflection of soil water condition and further reflect the degree of drought in farmland intuitively (Ma et al., 2000; Zhu et al., 2013; Zhang et al., 2016). And soil moisture is an important parameter for research on the land surface processes. It can affect climate change by changing the sensible heat, latent heat and long wave radiation fluxes from the surface to the atmosphere (Delworth et al., 1988; Delworth et al., 1993; Ma et al., 1999). Therefore, analyzing the spatial and temporal variations and regularity of relative soil moisture in different soil depths under different time and space backgrounds is important to grasp the changes of the soil moisture of farmland, utilize soil water resources rationally, and carry out further research on the land surface process system.

In recent years, many researchers have conducted a series of studies on the characteristics and influencing factors of relative soil moisture using measured data. Currently, researches mainly focus on the relationship between relative soil moisture and meteorological elements (Lu et al., 2011; Wang et al., 2013; Cho et al., 2014; Wang et al., 2015), soil properties (Zhang et al., 2004; Fang et al., 2005; Zuo et al., 2007; Zhou et al., 2015; Zhang et al., 2016; Zuo et al., 2018), land cover types (Zhang et al., 2003; Zhang et al., 2004; Broni et al., 2013), and soil depth (Wang et al., 2013; Zhu et al., 2014) in the research area, and explore the spatial and temporal variation characteristics and trends of relative soil moisture in specific areas. At present, research hot spots in China are mainly concentrated in the areas where hydrological and meteorological observation data are relatively abundant, such as the arid region of northwest China (Zhang et al., 2007; Wang et al., 2008; Zhang et al., 2011; Zhang et al., 2012), the eastern China monsoon region (Zuo et al., 2007; Zuo et al., 2018), the Loess Plateau (Chen et al., 2008; Lu et al., 2011), the Hengduan Mountainous (Zhu et al., 2013), and the middle-lower reaches of the Yellow River (Fang et al., 2005; Li et al., 2011; Wang et al., 2015). Due to the scarcity of observation sites on the Qinghai-Tibet Plateau, the research of point pattern is mainly carried out based on the measured data (Wan et al., 2012; Zhuo et al., 2015). In recent years, various inversion methods based on remote sensing technology have become more and more effective in researching large-scale soil moisture (Zhang et al., 2008; Younis et al., 2015). However, there are a lot of uncertainties in all kinds of inversion data, which cannot replace the measured data in the short term.

This study used geostatistical methods to research the spatial and temporal variation characteristics and regularity of relative soil moisture in China's farmland from 1993 to 2013. The research can form basic data of relative soil moisture over China, provide comparative verification data for soil moisture monitoring based on remote sensing technology, provide input parameters for regional land surface process model, and provide scientific decision-making support for agricultural, forestry and other management departments.

\section{Research area}

Based on the Comprehensive Agricultural Regionalization of China, this study analyzes the spatial and temporal variations of relative soil moisture in different regions of China's farm- 
land (NARC, 1981). The division method of the regions is based primarily on their agriculture production and geographic features (Ju et al., 2018). The classification divides China into 10 agricultural first-grade regions. Nine of them are on land, and one is called the Marine Fishery Region. These on land regions include Northeast Region, Inner Mongolia and along the Great Wall Region, Huang-Huai-Hai Plain Region, Loess Plateau Region, Middle-Lower Yangtze River Region, Southwest Region, South China Region, Gansu-Xinjiang Region, and Qinghai-Tibet Plateau Region (Figure 1). The above 10 agricultural first-grade regions reveal the most basic regional differences of agricultural production in China. On the one hand, they reflect the different combinations of agricultural natural conditions and natural resources in China, thus providing a variety of possibilities for the development of agriculture. On the other hand, it reflects the basic characteristics of the regional differentiation of agricultural production formed in the long-term historical development. The characteristics of each agricultural first-grade region are distinct, have great stability, and have a unique position in China (Deng 1982).

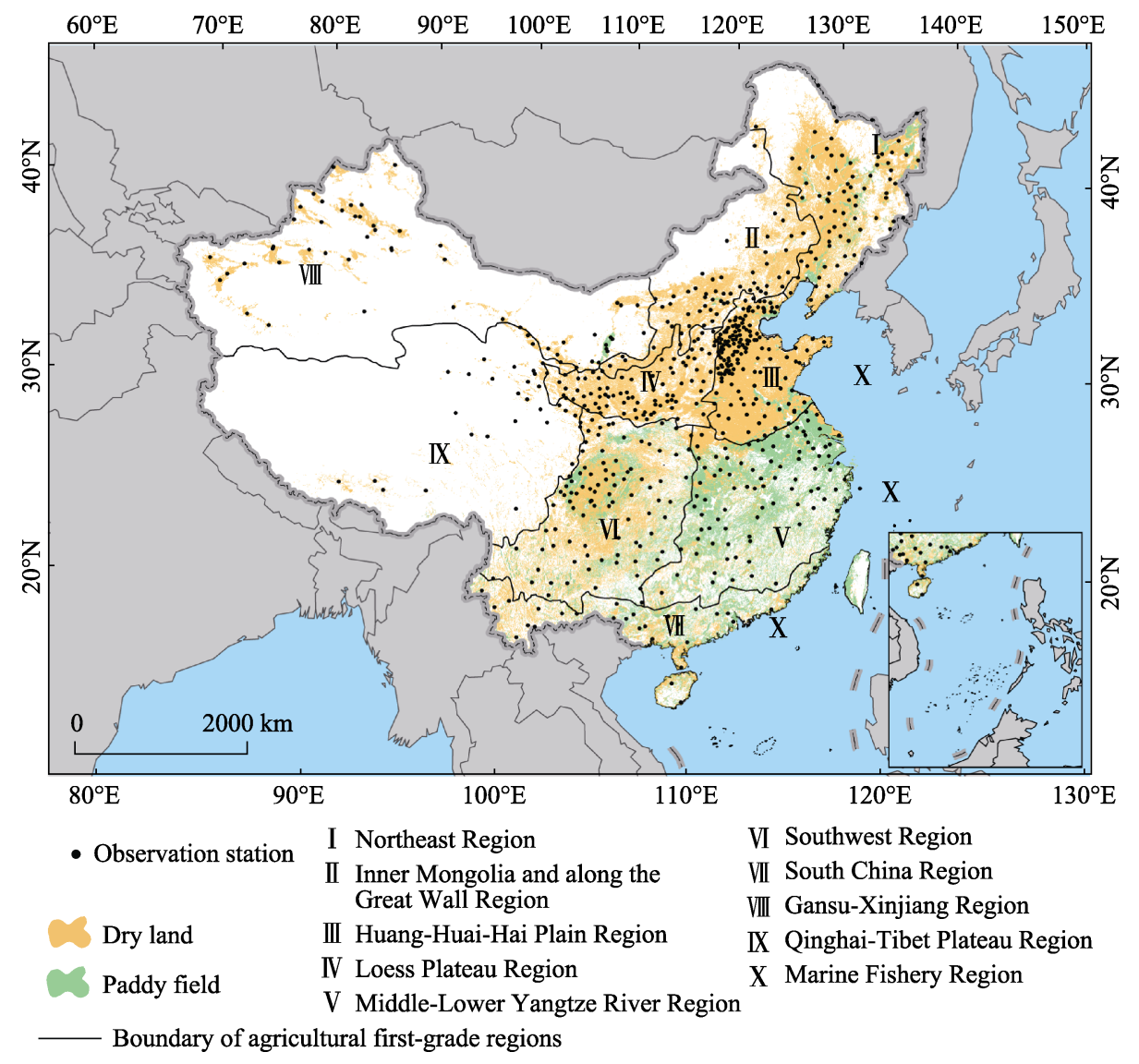

Figure 1 Distribution of relative soil moisture observation station

\section{Data and methods}

\subsection{Data source and processing}

Based on the ten-day data of relative soil moisture of 778 agricultural observation stations in 
China from 1993 to 2013, 653 stations with good time continuity, good location representation and trend test by Mann-Kendall were selected to carry out the research. Among them, the number of stations with time series of data beginning in 1993 was 338, and that in 2002 was 315 (Figure 1). Due to the scarcity of sites on the Qinghai-Tibet Plateau Region, 14 stations with relatively poor data status were selected as supplementary stations, including Lhasa, Linzhi, Gande, Huangyuan, Menyuan, Nomhon, Qumacai, Golmud, Zedang, Shigatse, Minhe, Delingha, Guide and Henan. Data of relative soil moisture and meteorological element were from the National Meteorological Information Center (http://data.cma.cn/site/index.html), all meteorological data passed the Mann-Kendall trend test, and the spatial distribution data of farmland were from the Resource and Environment Data Cloud Platform (http://www.resdc.cn/data.aspx DATAID=99). The classification method of the agricultural first-grade regions is based on the China Comprehensive Agricultural Division (NARC, 1981).

According to the ten-day data of the relative soil moisture of the three soil depths $(10 \mathrm{~cm}$, $20 \mathrm{~cm}$ and $50 \mathrm{~cm}$ ) during the period of 1993 to 2013 at each station, the multi-year average in each season and annual average of relative soil moisture at each soil depth from 1993 to 2013 were calculated as follows.

$$
R_{(h, s)}=\left[\sum_{i=1993}^{2013} \sum_{j=n}^{m} X_{i j}+Y_{i j}+Z_{i j}\right] /\left(N_{X}+N_{Y}+N_{Z}\right)
$$

where $h$ is the depth of the soil depth $(10 \mathrm{~cm}, 20 \mathrm{~cm}, 50 \mathrm{~cm}) ; s$ is the time scale (multi-year spring average, multi-year summer average, multi-year autumn average, multi-year winter average, multi-year average); $i$ indicates the year of 1993 to 2013; $j$ represents the months included in the required time scale, $n$ is the month where $j$ starts, and $m$ is the month where $j$ ends; $M_{X}, N_{Y}$ and $N_{Z}$ indicate the number of ten-days in which observational data exist in the first, middle and last ten-days of each month from 1993 to 2013, respectively. The calculation results of each station were calculated, analyzed and discussed by Kriging interpolation according to the agricultural division.

The annual average $R_{(h, i)}$ of relative soil moisture in the three soil depths for each season at each station were respectively established a linear regression equation with time $\left(t_{i}\right)$, as shown in formula (2).

$$
R_{(h, i)}=a+b t_{i}
$$

where $i$ represents the year and $b$ is the tendency rate of interannual variation of relative soil moisture in each season. The positive $(b>0)$ tendency rate indicates that the relative soil moisture increases with time, and the negative $(b<0)$ tendency rate indicates a downward trend.

\subsection{Methods}

Due to the complexity and diversity of crop type, irrigation time and type, meteorological factors, uniform crop evapotranspiration coefficient cannot be used on a large spatial scale. Therefore, the potential evaporation is selected as one of the meteorological factors for analysis. The potential evaporation of each station is based on the daily data of six meteorological elements including daily maximum temperature, daily minimum temperature, daily average temperature, average relative humidity, average wind speed and sunshine hours 
during the research period, and the Penman-Monteith model revised by the World Food and Agriculture Organization (FAO) in 1998 was used to calculate (Allen et al., 2006; Zhu et al., 2011).

At present, most researches on the relationship between soil moisture and environmental factors use Kring interpolation method based on geostatistics and analysis in ArcGIS, this method is based on spatial correlation model (Yamamoto, 2007), and its advantage is that it has strong applicability when the terrain and meteorology are heterogeneous, which it can not only reflect the consistency of geographical elements on a larger spatial and temporal scale, but also reflect the uniqueness of specific regions (Yamamoto, 2007; Zhu et al., 2016).

\section{Results and analysis}

\subsection{Spatial distribution of relative soil moisture}

The spatial distribution of the multi-year average relative soil moisture (Figure 2) showed that the relative soil moisture value was generally greater than $60 \%$ in China's farmland, and there were spatial distribution differences among regions, soil depths and seasons.

The relative soil moisture of $10 \mathrm{~cm}$ depth. In spring, the areas with relative soil moisture less than $60 \%$ were mainly distributed in the Loess Plateau Region, Inner Mongolia and along the Great Wall Region, the southwest of Southwest Region, the Pearl River Delta of the South China Region, the Hangzhou Bay coast of Middle-Lower Yangtze River Region, the north-central part of Huang-Huai-Hai Plain Region, and the Ningxia Plain of Gansu-Xinjiang Region. The relative soil moisture values of other areas were generally greater than $60 \%$. Among them, relative soil moisture in the eastern region of Northeast Region, most of the Middle-Lower Yangtze River Region, and most of Southwest Region were greater than $80 \%$. In summer, except for Gansu-Xinjiang Region, Loess Plateau Region and Inner Mongolia and along the Great Wall Region, the relative soil moisture in other regions were generally greater than $60 \%$. In the central part of the Middle-Lower Yangtze River Region and the southern part of Southeast Region, the area where relative soil moisture was more than $80 \%$ in summer was smaller than that in spring. The relative soil moisture in the southeastern part of the Huang-Huai-Hai Plain Region and the vast area at the junction of Southwest Region and South China Region increased significantly in summer compared with that in spring. In autumn, the area where the relative soil moisture was less than $60 \%$ was sporadically distributed at the junction of Southwest Region and Middle-Lower Yangtze River Region, mainly distributed to the north of the Yangtze River, and showed a shrinking trend from east to west. The area where the relative soil moisture was greater than $80 \%$ was distributed in the eastern part of Northeast Region, most of Southwest Region, the southwestern and northeastern parts of Middle-Lower Yangtze River Region, and the southeastern part of the Huang-Huai-Hai Plain Region. In winter, the area where the relative soil moisture was less than $60 \%$ obviously enlarged. The relative soil moisture in the north of Tianshan Mountains of Gansu-Xinjiang Region, the northeastern part of the Qinghai-Tibet Plateau Region, most of Inner Mongolia and along the Great Wall Region is less than $45 \%$. The area with relative soil moisture greater than $80 \%$ tended to shrink in Southwest Region, while it tended to expand at different degrees in Middle-Lower Yangtze River Region, Huang-Huai-Hai Plain Region, and Northeast Region. From the multi-year average 
(a) Aunnual mean $10 \mathrm{~cm}$

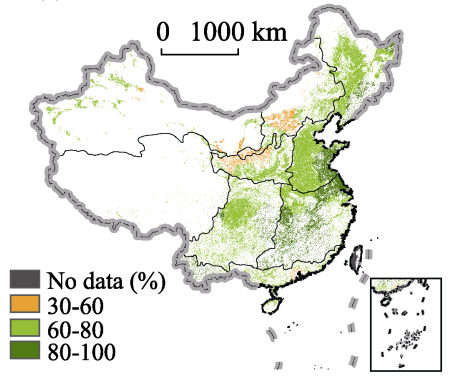

(d) Spring $10 \mathrm{~cm}$

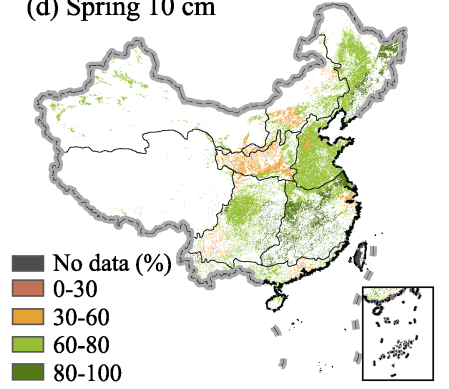

(g) Summer $10 \mathrm{~cm}$

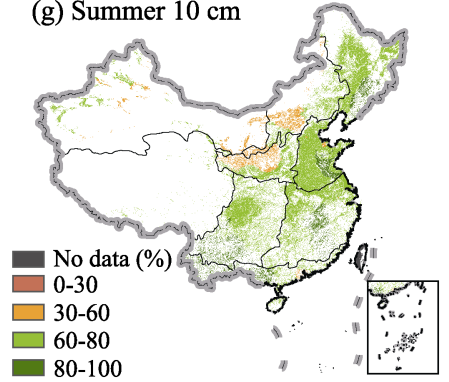

(j) Autumn $10 \mathrm{~cm}$

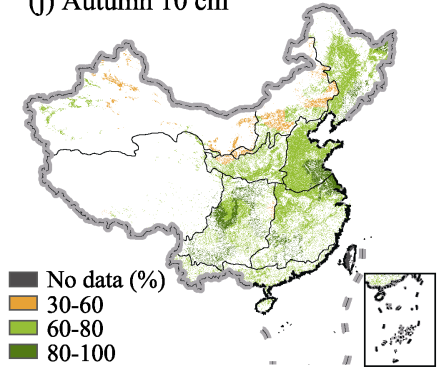

(m) Winter $10 \mathrm{~cm}$

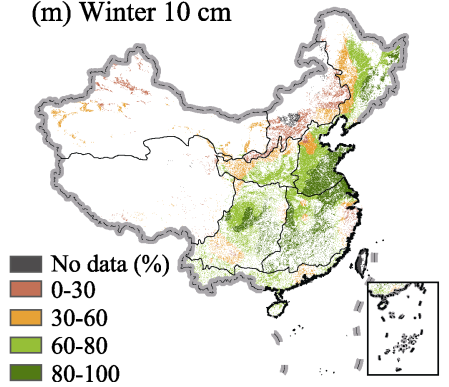

(b) Annual mean $20 \mathrm{~cm}$

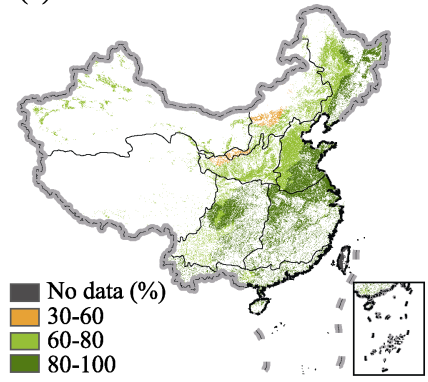

(e) Spring $20 \mathrm{~cm}$

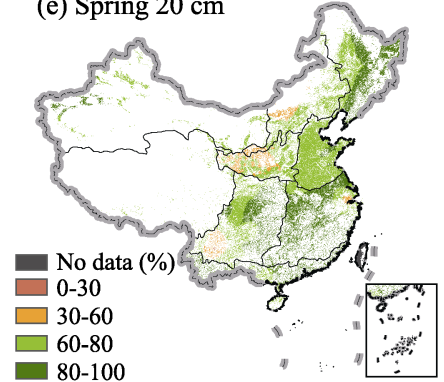

(h) Summer $20 \mathrm{~cm}$

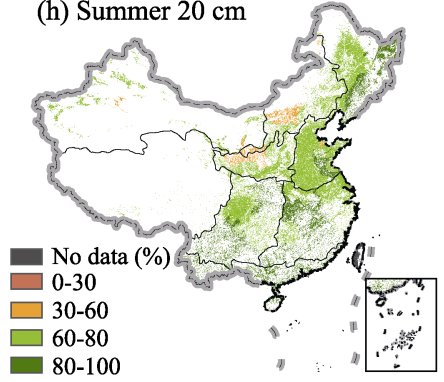

(k) Autumn $20 \mathrm{~cm}$

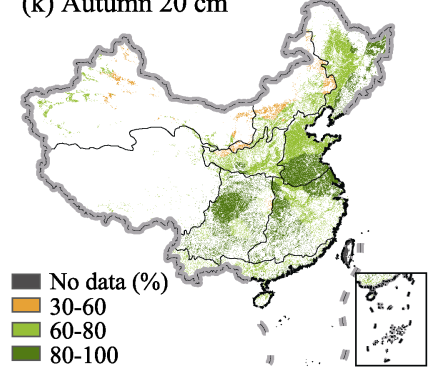

(n) Winter $20 \mathrm{~cm}$

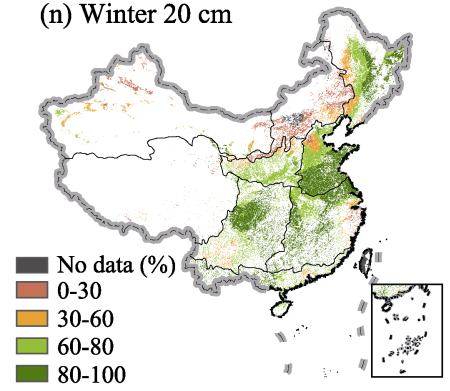

(c) Annual mean $50 \mathrm{~cm}$

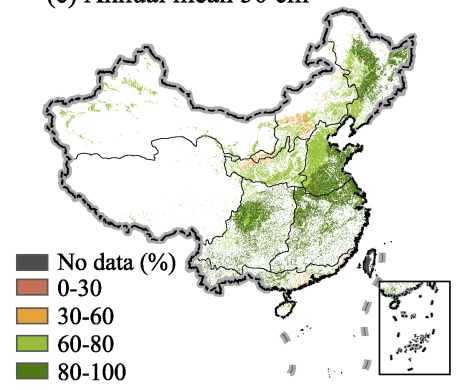

(f) Spring $50 \mathrm{~cm}$

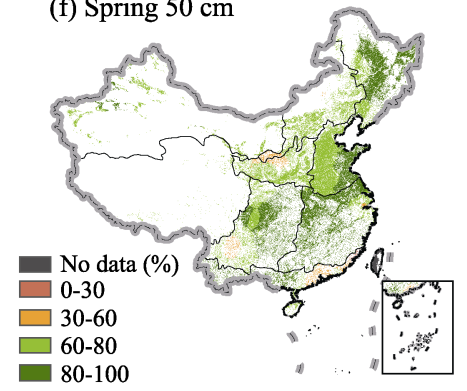

(i) Summer $50 \mathrm{~cm}$

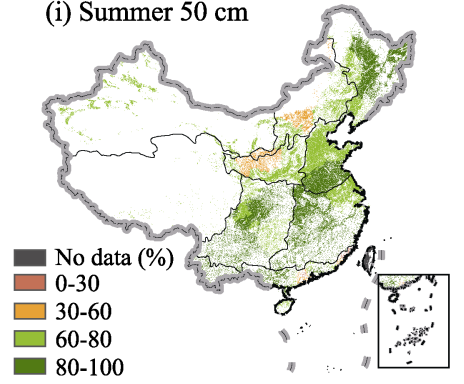

(1) Autumn $50 \mathrm{~cm}$

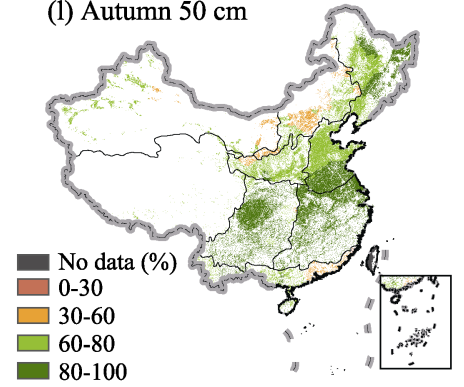

(o) Winter $50 \mathrm{~cm}$

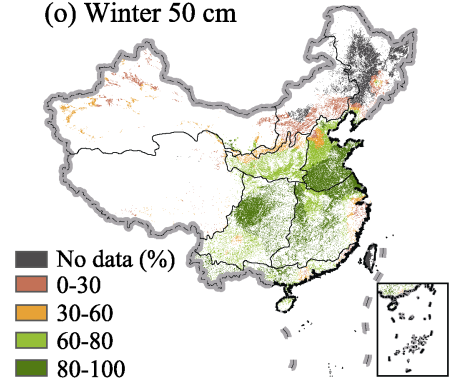

Figure 2 Distribution of relative soil moisture in farmland 
value of the relative soil moisture at this depth, areas where the relative soil moisture was less than $60 \%$ were mainly distributed at the junction of Gansu-Xinjiang Region, Loess Plateau Region, and Inner Mongolia and along the Great Wall Region.

The relative soil moisture of $20 \mathrm{~cm}$ depth. In spring, the areas where the relative soil moisture was less than $60 \%$ were mainly distributed in Southwest Region, Inner Mongolia and along the Great Wall Region, and the west-central Loess Plateau Region. Among them, relative soil moisture that was less than $30 \%$ sporadically appeared in the southwestern part of Southwest Region. The relative soil moisture in other areas is more than $60 \%$, and that in the eastern part of Northeast Region, the southeastern part of Huang-Huai-Hai Plain Region, most of Middle-Lower Yangtze River Region, most of Southwest Region, and most of South China Region was greater than $80 \%$. In summer, the area where the relative soil moisture was less than $60 \%$ was concentrated in most of Loess Plateau Region, southwest of the Inner Mongolia and along the Great Wall Region. In the Huang-Huai-Hai Plain Region near the Yellow River Estuary and the south Tianshan Mountains of Gansu-Xinjiang Region, there was also a sporadic distribution. The area where the relative soil moisture was greater than $80 \%$ tended to decrease in Northeast Region and Middle-Lower Yangtze River Region but expanded in the Huang-Huai-Hai Plain Region, South China Region and Southwest Region. In autumn, the area where the relative soil moisture was less than $60 \%$ further shrank in the Loess Plateau Region, Inner Mongolia and along the Great Wall Region, and the Huang-Huai-Hai Plain Region, but it expanded at the junction of the Gansu-Xinjiang Region, Southwest Region, and Middle-Lower Yangtze River Region. The area where the relative soil moisture was more than $80 \%$ showed a significant expanded trend in southern Huang-Huai-Hai Plain Region, Middle-Lower Yangtze River Region, Southwest Region, the southern Loess Plateau Region, and the eastern part of the Qinghai-Tibet Plateau Region, but shrank in South China Region and Northeast Region. In winter, the area where the relative soil moisture was less than $60 \%$ obviously enlarged, and were mainly distributed in the majority of Gansu-Xinjiang Region, most of the Qinghai-Tibet Plateau Region, most of the areas of the Inner Mongolia and along the Great Wall Region, the western part of Northeast Region, the southwestern part of Southwest Region, coastal areas of Fujian and Zhejiang in Middle-Lower Yangtze River Region, and the Pearl River Estuary in South China Region. Among them, the relative soil moisture in most of the Inner Mongolia and along the Great Wall Region, most of the Qinghai-Tibet Plateau Region, the coastal areas of Fujian and Zhejiang in Middle-Lower Yangtze River Region, the western part of the Gansu-Xinjiang Region, and the northwest of the Huang-Huai-Hai Plain Region was less than $30 \%$. Areas with relative soil moisture greater than $80 \%$ in winter did not change much compared to that in autumn. From the multi-year average value of relative soil moisture, the areas where the relative soil moisture was less than $60 \%$ were concentrated in the northeastern part of Loess Plateau Region, the southwestern Inner Mongolia and along the Great Wall Region. Among them, most of the South China Region, most of the Middle-Lower Yangtze River Region, the eastern part of Huang-Huai-Hai Plain Region, the eastern part of Northeast Region, and the eastern part of Southwest Region have a relative soil moisture greater than $80 \%$.

The relative soil moisture of $50 \mathrm{~cm}$ depth. In spring, the areas where the relative soil moisture was less than $60 \%$ were mainly distributed in the junction of Loess Plateau Region and Inner Mongolia and along the Great Wall Region, the southwestern part of Southwest Region, and the central and eastern parts of South China Region and were sporadically dis- 
tributed in the north area of the Inner Mongolia and along the Great Wall Region, and Hangjiahu Plain in Middle-Lower Yangtze River Region. The relative soil moisture of other areas was greater than $60 \%$, and it was more than $80 \%$ in Northeast Region, South China Region, Middle-Lower Yangtze River Region, Southwest Region, and the southeastern part of the Huang-Huai-Hai Plain Region. In summer, the area where the relative soil moisture was less than $60 \%$ shrank in the south of the Yangtze River, and expanded in the northern part. There was no obvious distribution in South China Region, Southwest Region, and Middle-Lower Yangtze River Region, but in the Loess Plateau Region and the Inner Mongolia along the Great Wall, the expansion trend was obvious. The relative soil moisture in other areas was greater than $60 \%$, and the farmland area with the relative soil moisture greater than $80 \%$ was reduced in Gansu-Xinjiang Region, and in other agricultural first-grade regions it was enlarged. In autumn, the area where the relative soil moisture was less than $60 \%$ was distributed in various agricultural regions north of the Yangtze River, and the eastern part of the South China Region, the junction of which with Middle-Lower Yangtze River Region was even less than $40 \%$. The relative soil moisture in other regions is greater than $60 \%$, and the areas with relative soil moisture value more than $80 \%$ was concentrated in most of Northeast Region, most of the Middle-Lower Yangtze River Region, most of Southwest Region, and the southern part of the Huang-Huai-Hai Plain Region. There was also a sporadic distribution in the southern part of the Loess Plateau Region. In winter, the area with relative soil moisture less than $60 \%$ was widely distributed. In the southern part of Huang-Huai-Hai Plain Region, the central and western parts of South China Region, most of Middle-Lower Yangtze River Region, and the northeastern part of Southwest Region, the relative soil moisture was greater than $80 \%$. From the perspective of multi-year average value of relative soil moisture, the areas where the relative soil moisture was less than $60 \%$ were mainly concentrated in the Loess Plateau Region, Inner Mongolia and along the Great Wall Region. The relative soil moisture of other areas was more than $60 \%$.

From the perspective of the change of relative soil moisture with season, the areas with high relative soil moisture values in the different soil depths had a tendency to expand northward and westward with the transition of summer monsoon, that is, the area with high relative soil moisture value expanded, and the area with low relative soil moisture value gradually shrank. The distribution area of high relative soil moisture value reached the maximum in autumn, and the distribution area of low relative soil moisture value is the largest in winter. The area with high relative soil moisture value of each season is most widely distributed in $50 \mathrm{~cm}$ soil depth.

\subsection{Spatial differences in interannual variations in relative soil moisture}

From interannual variation of the seasonal average and the annual average of relative soil moisture (Figure 3), the tendency rate of interannual relative soil moisture during the period from 1993 to 2013 was generally between -2.9 and 5, and that belonging to positive and negative were interlaced in China, and changed with season.

In spring, the areas with negative interannual tendency rate in Qinghai-Tibet Plateau Region, Northeast Region, Southwest Region, and Gansu-Xinjiang Region expanded with the increase of the soil depth. The areas with positive interannual tendency rate in Inner Mongolia and along the Great Wall Region, Loess Plateau Region, and Middle-Lower Yangtze 
(a) Annual mean $10 \mathrm{~cm}$

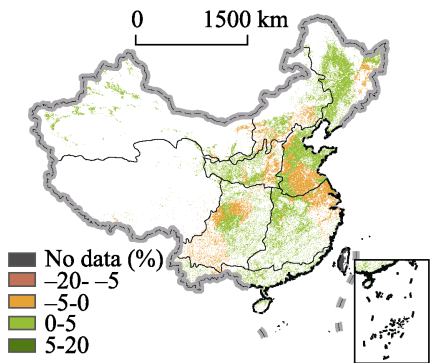

(d) Spring $10 \mathrm{~cm}$

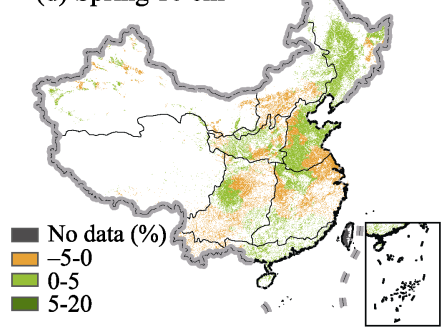

(g) Summer $10 \mathrm{~cm}$

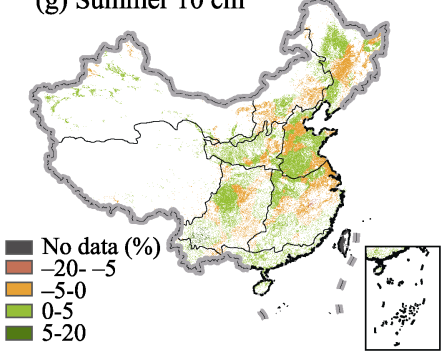

(j) Autumn $10 \mathrm{~cm}$

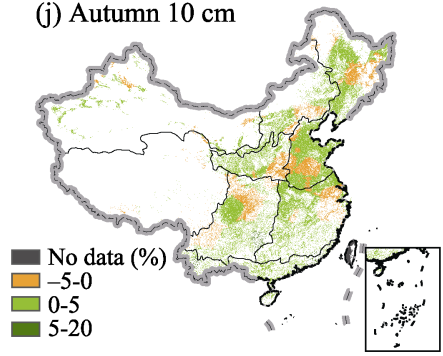

(m) Winter $10 \mathrm{~cm}$

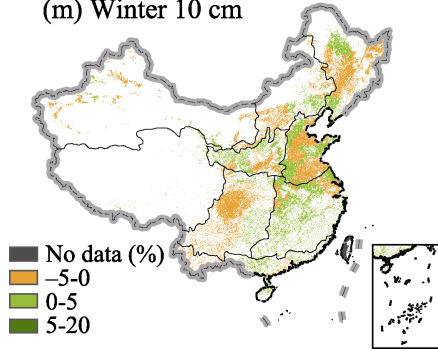

(b) Annual mean $20 \mathrm{~cm}$

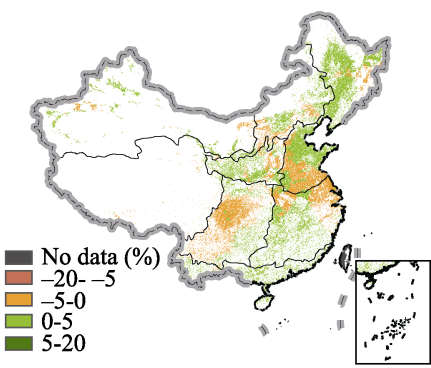

(e) Spring $20 \mathrm{~cm}$

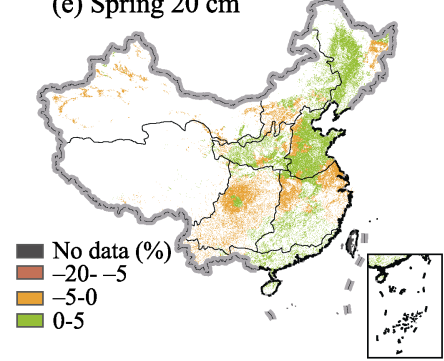

(h) Summer $20 \mathrm{~cm}$

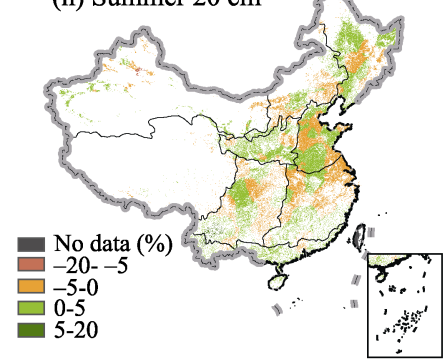

(k) Autumn $20 \mathrm{~cm}$

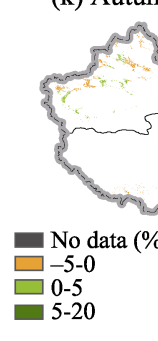

(n) Winter $20 \mathrm{~cm}$

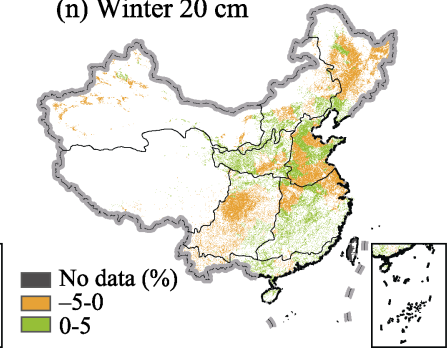

(c) Annual mean $50 \mathrm{~cm}$

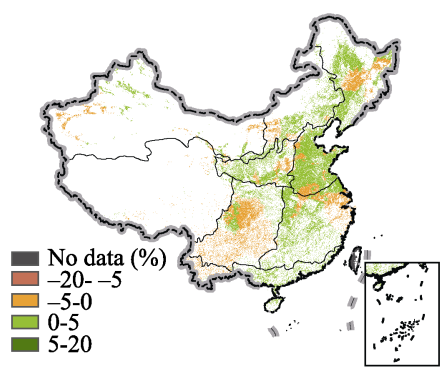

(f) Spring $50 \mathrm{~cm}$

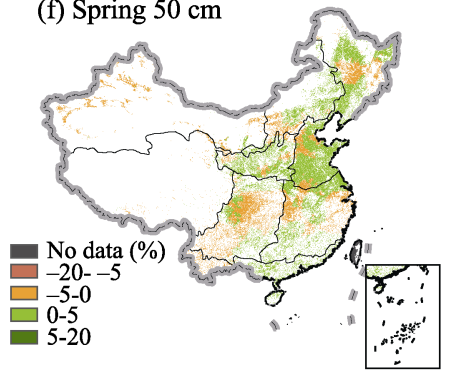

(i) Summer $50 \mathrm{~cm}$

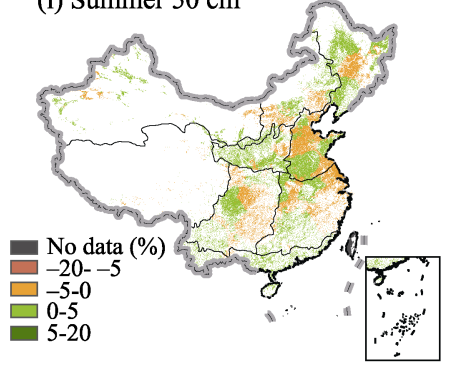

(1) Autumn $50 \mathrm{~cm}$

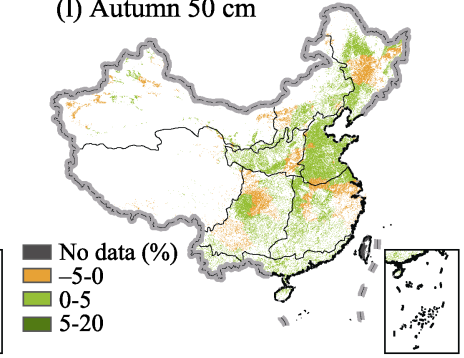

(o) Winter $50 \mathrm{~cm}$

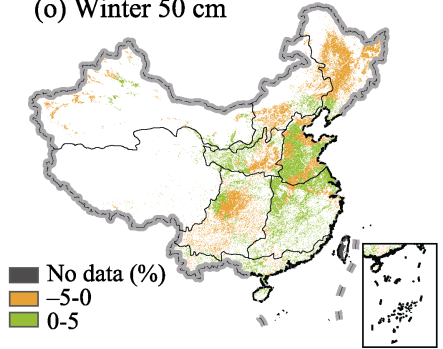

Figure 3 Spatial distribution of interannual variability of relative soil moisture in farmland

River Region expanded with the increase of the soil depth. The spatial distribution of positive and negative interannual tendency rate of various soil depths in South China Region 
showed good consistency. The interannual tendency rate in the west of the Yunnan-Guangxi border was mainly negative, and in the eastern region was mainly positive. The areas with interannual tendency rate in Southwest Region, Huang-Huai-Hai Plain Region, and Middle-Lower Yangtze River Region expanded with the increase of soil depth. The relative soil moisture to $10 \mathrm{~cm}$ soil depth in the Middle-Lower Yangtze River Region and that to $20 \mathrm{~cm}$ soil depth in the northern part of the Tianshan Mountains in Gansu-Xinjiang Region have a tendency rate ranging from $-20 \% /$ a to $-5 \% / \mathrm{a}$. In autumn, the distribution of farmland areas with interannual tendency rate being $0-5 \% /$ a was the widest. In South China Region, there was no area with negative interannual tendency rate at each soil depth and the interannual tendency rate was within the range of $0-5 \% / \mathrm{a}$. In the eastern part of South China Region, there was partial area with an interannual tendency rate being 5\%/a-20\%/a. The areas with positive and negative interannual tendency rate in other agricultural first-grade regions were characterized by interlaced phase distribution. In winter, the distribution of negative interannual tendency rate was more extensive than other seasons, and concentrated in Northeast Region, Gansu-Xinjiang Region, Inner Mongolia and along the Great Wall Region, Huang-Huai-Hai Plain Region and Southwest Region, while the interannual tendency rate was negative in the west of the Pearl River Estuary in the South China Region and at the junction with Southwest Region for the first time.

Judging from the interannual variation of the annual average, there were areas with negative interannual tendency rate in different soil depths in Southwest Region and most of Qinghai-Tibet Plateau Region. At the junction of Gansu-Xinjiang Region and Inner Mongolia and along the Great Wall Region, the junction of Middle-Lower Yangtze River Region and Huang-Huai-Hai Plain Region, and the junction of Huang-Huai-Hai Plain Region, Loess Plateau Region and Inner Mongolia and along the Great Wall Region, there were areas with negative interannual tendency rate at each soil depth. With the increase of soil depth, the areas with negative interannual tendency rate in various agricultural first-grade regions show an expanded trend from southeast to northwest.

From the perspective of the trends of interannual tendency rate with different seasons, the area with a negative annual interannual tendency rate was most widely distributed in winter. In summer and autumn, the interannual tendency rate in each agricultural first-grade region was mainly positive.

\subsection{Interannual variation of relative soil moisture}

The interannual variation of the annual average relative soil moisture of farmland in China had strong regularity (Figure 4). The trend of annual average relative soil moisture value of different soil depths in each agricultural first-grade region had strong consistency. The change in South China Region is greater than that in other regions. The relative soil moisture values in the Middle-Lower Yangtze River Region and Southwest Region were higher than those in other regions, while the relative soil moisture values in the Loess Plateau Region, Inner Mongolia and along the Great Wall Region, and Gansu-Xinjiang Region is significantly lower than those in other regions, and there were less differences among different soil depths in Inner Mongolia and the Great Wall Region.

In Northeast Region, the interannual tendency rates of relative soil moisture in $10 \mathrm{~cm}, 20$ $\mathrm{cm}$ and $50 \mathrm{~cm}$ soil depths were $0.18 \% / \mathrm{a}, 0.14 \% / \mathrm{a}$, and $0.011 \% / \mathrm{a}$, respectively. In Gansu-Xinjiang Region, they were $0.26 \% / \mathrm{a},-0.15 \% / \mathrm{a}$, and $-0.09 \% / \mathrm{a}$, respectively. In South 


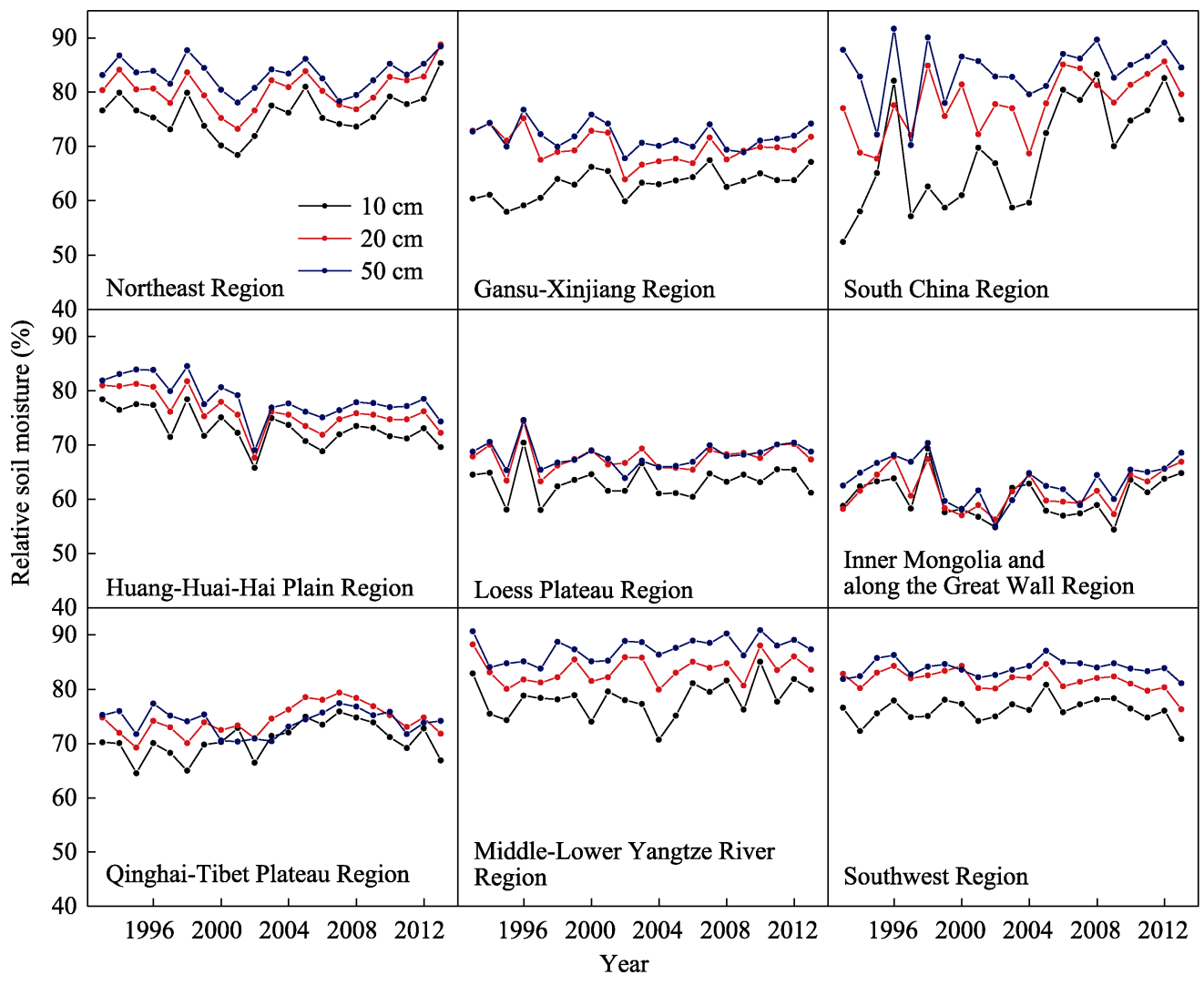

Figure 4 Interannual variation of relative soil moisture in different agricultural first-grade regions

China Region, they were 1.04\%/a, 0.51\%/a, and 0.24\%/a, respectively. In Huang-Huai-Hai Plain Region, they were $-0.31 \% / \mathrm{a},-0.35 \% / \mathrm{a}$, and $-0.37 \% / \mathrm{a}$, respectively. In Loess Plateau Region, they were $0.017 \% / \mathrm{a}, 0.049 \% / \mathrm{a}$, and $0.028 \% / \mathrm{a}$, respectively. In Inner Mongolia and along the Great Wall Region, they were $-0.020 \% / \mathrm{a}, 0.079 \% / \mathrm{a}$, and $-0.022 \% / \mathrm{a}$, respectively. In the Qinghai-Tibet Plateau Region, they were $0.21 \% / \mathrm{a}, 0.20 \% / \mathrm{a}$, and $0.0084 \% / \mathrm{a}$, respectively. In Southwest Region, they were $0.0026 \% / \mathrm{a},-0.16 \% / \mathrm{a}$, and $-0.005 \% / \mathrm{a}$, respectively. In the Middle-Lower Yangtze River Region, they were $0.14 \% / \mathrm{a}, 0.08 \% / \mathrm{a}$, and $0.15 \% / \mathrm{a}$, respectively. Since 1993, the interannual tendency rates of relative soil moisture in Huang-Huai-Hai Plain Region were negative, while in other regions they were generally positive. The fastest increasing rate of relative soil moisture appeared in the $20 \mathrm{~cm}$ soil depth in South China Region, and the slowest was in the $10 \mathrm{~cm}$ soil depth in Southwest Region. The highest negative tendency rate of relative soil moisture was in the $50 \mathrm{~cm}$ depth in the Huang-Huai-Hai Region, and the lowest was in the $50 \mathrm{~cm}$ soil depth in Southwest Region.

\subsection{Monthly changes of relative soil moisture}

The relative soil moisture values increased with the increase of soil depth in each month (Figure 5). There was a regional difference in the monthly trend of relative soil moisture, but there was a strong consistency in the monthly trend of relative soil moisture in different soil depths in the same agricultural first-grade region. There were also obvious regional differences in the monthly variation of relative soil moisture. The monthly variations in Middle-Lower Yangtze River Region, Northeast Region and the Qinghai-Tibet Plateau Region 


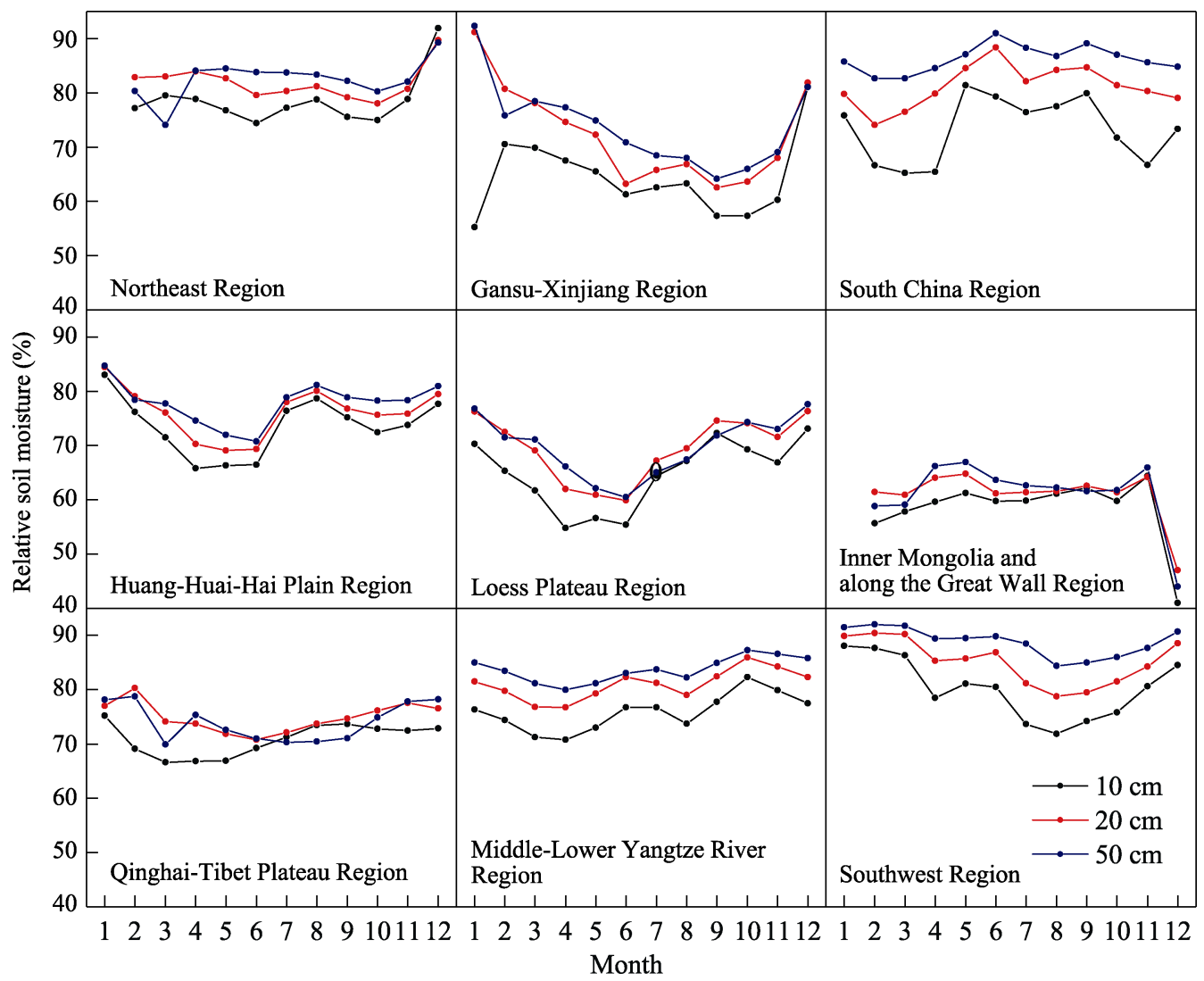

Figure 5 Monthly variation of relative soil moisture in different agricultural first-grade regions

was relatively small, while they were relatively large in the Gansu-Xinjiang Region, South China Region, Inner Mongolia and along the Great Wall Region. The monthly variation of relative soil moisture in different regions shows a regularity of decreasing with the increase of soil depth. The relative soil moisture values of different soil depths in each month in Inner Mongolia and along the Great Wall Region were lower than those in other regions.

\section{Discussion}

\subsection{Influence of main meteorological elements on relative soil moisture}

In spring, except that the relative soil moisture of farmland was negatively correlated with precipitation in the western part of the Hexi Corridor in Gansu-Xinjiang Region, the relative soil moisture in other region was generally positively correlated with precipitation (Figure 6). In most of the Middle-Lower Yangtze River Region, most of the South China Region, most of the Huang-Huai-Hai Plain Region, most of the Inner Mongolia and along the Great Wall Region, the eastern part of Northeast Region, the southwestern part of the Qinghai-Tibet Plateau Region, the southern part of the Loess Plateau Region, and the eastern part of Southwest Region, there was a strong positive correlation between relative soil moisture and precipitation, and the correlation coefficient was between 0.3 and 0.7 . In autumn, the areas where relative soil moisture and precipitation were strong positively correlated in Northeast Region, Middle-Lower Reaches Yangtze River Region, Huang-Huai-Hai Plain Region and the Loess Plateau Region increased, while those in Southwest Region and South China 
(a) Spring precipitation

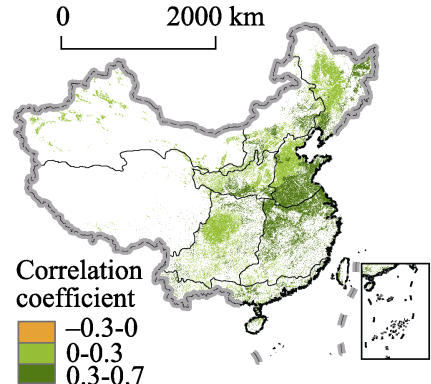

(d) Summer precipitation

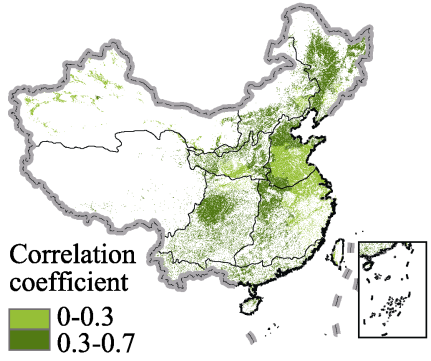

(g) Autumn precipitation

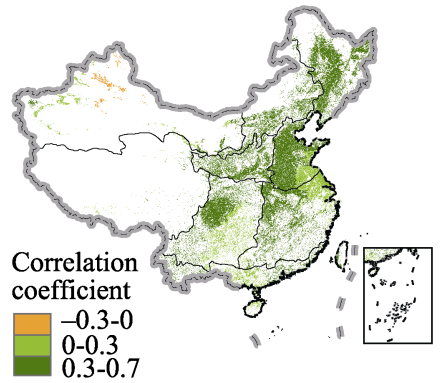

(j) Winter precipitation

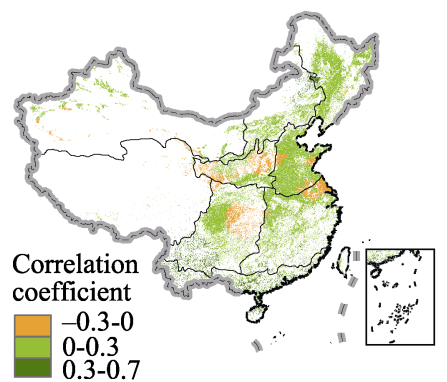

(b) Spring potential evaporation

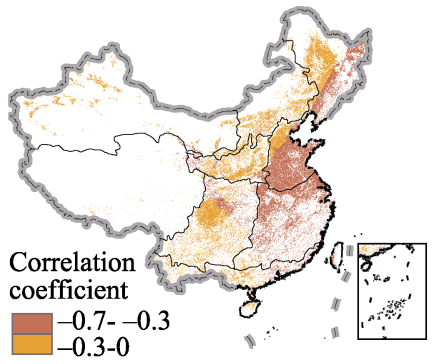

(e) Summer potential evaporation

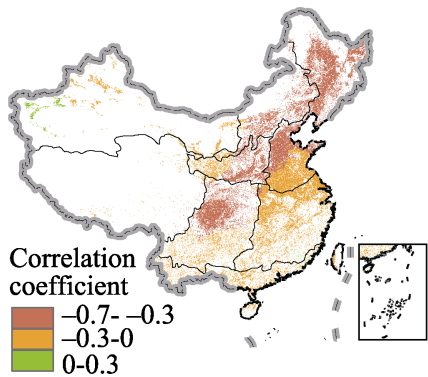

(h) Autumn potential evaporation

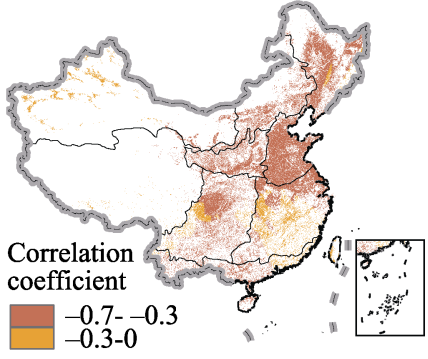

(k) Winter potential evaporation

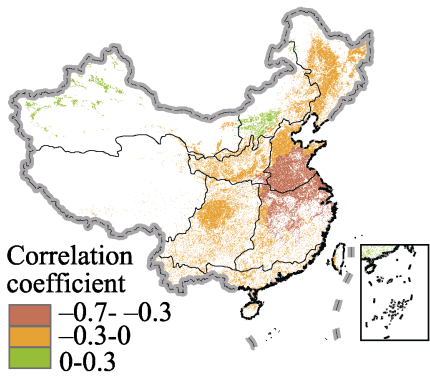

(c) Spring temperature

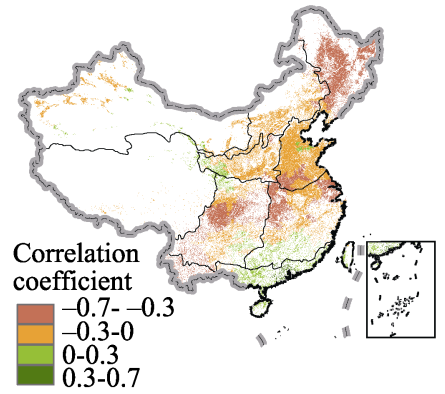

(f) Summer temperature

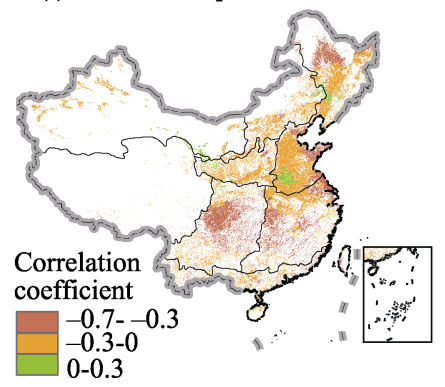

(i) Autumn temperature

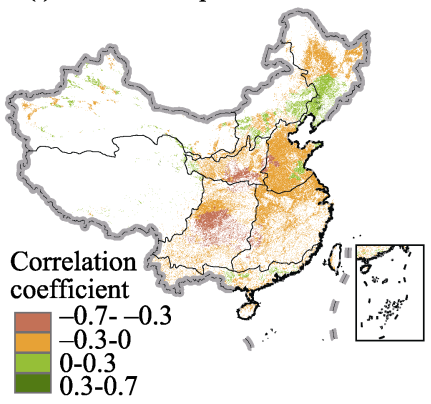

(l) Winter temperature

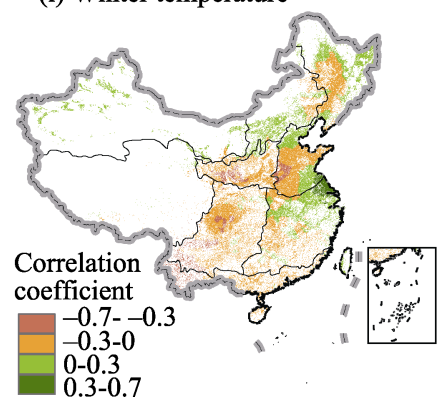

Figure 6 Spatial distribution of correlation coefficients between main meteorological factors and relative soil moisture

Region decreased. In winter, the areas where relative soil moisture was positively correlated with precipitation were concentrated in most of South China Region and the southwestern part of Southwest Region, and there was also a sporadic distribution at the junction of Northeast Region and Inner Mongolia and along the Great Wall Region. The area where the relative soil moisture was negatively correlated with precipitation was scattered in China's 
non-monsoon region, mainly because precipitation in the non-monsoon region in winter is mainly snowfall, which will not be infiltrated to the soil immediately, and the absorption ability of soil after freezing is greatly reduced.

The relative soil moisture and potential evaporation of farmland were generally negatively correlated in each season (Figure 6). In spring, the relative soil moisture of farmland was negatively correlated with potential evaporation, and the correlation was especially strong in the eastern part of Northeast Region, most of Huang-Huai-Hai Plain Region, most of Middle-Lower Yangtze River Region, the eastern part of South China Region, the eastern part of Southwest Region, the Loess Plateau Region and the junction of the Gansu-Xinjiang Region and Qinghai-Tibet Plateau Region. In summer, the relative soil moisture and potential evaporation in the eastern margin of the Tarim Basin of Gansu-Xinjiang Region and the southern part of Middle-Lower Yangtze River Region were positively correlated. In Southwest Region, Inner Mongolia and along the Great Wall Region, Northeast Region, and the Loess Plateau, the area where relative soil moisture and potential evaporation was negatively correlated significantly expanded, but it has shown a trend of shrinking in Middle-Lower Yangtze River Region, Gansu-Xinjiang Region, Qinghai-Tibet Plateau Region, Huang-Huai-Hai Plain Region, and South China Region. In autumn, there was a strong negative correlation between relative soil moisture and potential evaporation in farmland. The farmland areas with negative correlation from -0.3 to 0 were mainly distributed in most of Gansu-Xinjiang Region, the southern part of Qinghai-Tibet Plateau Region, the eastern part of South China Region, and Middle-Lower Yangtze River Region. In winter, the areas where relative soil moisture and potential evaporation are positively correlated were widely distributed in the western part of Gansu-Xinjiang Region, the southeastern part of Inner Mongolia and along the Great Wall Region.

The spatial distribution of the correlation coefficient between relative soil moisture and temperature in farmland varied greatly seasonally (Figure 6). In spring, the relative soil moisture was generally negatively correlated with temperature. The areas where relative soil moisture was strongly negatively correlated were mainly distributed in most of Northeast Region, southwestern part of Huang-Huai-Hai Plain Region, northern part of Middle-Lower Yangtze River Region, most of Southwest Region, and the eastern part of South China Region. In addition, farmland with positive correlation between relative soil moisture and temperature was widely distributed in the southeastern part of Southwest Region, southern part of Middle-Lower Yangtze River Region, and the eastern part of South China Region, among these regions, the positive correlation was strong in the Pearl River Estuary. The areas where relative soil moisture and temperature was positively correlated were also found in the northeastern part of Southwest Region, the southwestern part of Loess Plateau Region, the northeastern part of Qinghai-Tibet Plateau Region, and Hexi Corridor of Gansu-Xinjiang Region, and were scattered in the eastern part of Huang-Huai-Hai Plain Region and the western part of Gansu-Xinjiang Region. In summer, the area where the relative soil moisture is positively correlated with temperature was generally shrinking, but it expanded at the junction of Northeast Region with the Inner Mongolia and along the Great Wall Region, and the Huang-Huai-Hai Plain Region. In autumn, the areas where relative soil moisture was positively correlated with temperature were mainly distributed in the southern part of Northeast Region, most of the Qinghai-Tibet Plateau Region, most of the Gansu-Xinjiang Region, the western part of the Loess Plateau Region, the Inner Mongolia and along the Great Wall Region, and the southeastern part of Huang-Huai-Hai Plain Region, and was sporadically distributed in 
South China Region. The areas where relative soil moisture had a strong negative correlation with temperature were located in the central part of Southwest Region, the southwestern part of Middle-Lower Yangtze River Region, the central part of the Huang-Huai-Hai Plain Region, and the southern part of the Loess Plateau Region. In winter, areas with the relative soil moisture positively correlated with temperature were found in the majority of Gansu-Xinjiang Region, most of Inner Mongolia and along the Great Wall Region, the eastern part of Northeast China Region, the northern part of Middle-Lower Yangtze River Region, and the southeastern and northern parts of the Huang-Huai-Hai Plain Region. There was a strong negative correlation between relative soil moisture and temperature in the southern part of the Loess Plateau Region, the western part of the Huang-Huai-Hai Plain Region, the western part of South China Region, and the southwestern part of Southwest Region.

\subsection{Differences in relative soil moisture of paddy fields and dry land}

Most of the paddy fields were in the monsoon region with sufficient precipitation and irrigation water source, and the annual average relative soil moisture in different soil depths were higher than those in the dry land (Figure 7). The relative soil moisture value in $20 \mathrm{~cm}$ and 50 $\mathrm{cm}$ depth soils of more than $85 \%$ of the paddy fields exceeded $80 \%$, while it to $10 \mathrm{~cm}$ soil depth was mostly between $60 \%$ and $80 \%$. The relative soil moisture in $10 \mathrm{~cm}$ and $20 \mathrm{~cm}$ depth of more than $50 \%$ dry land was between $60 \%$ and $80 \%$, while it to $50 \mathrm{~cm}$ depth was mostly between $60 \%$ and $80 \%$ (Figure 2).

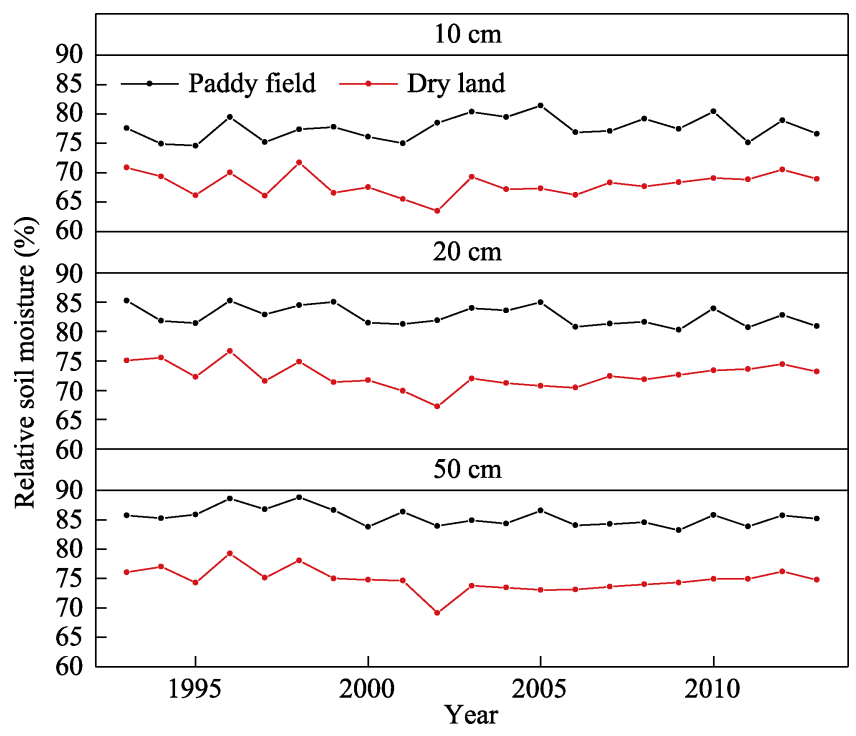

Figure 7 Interannual variation of relative soil moisture in different types of farmland

In summer, the correlations between relative soil moisture and precipitation, and potential evaporation in dry land was more significant than those in paddy fields. The correlation between relative soil moisture and temperature in paddy fields was stronger than that in dry land. In autumn, the correlations between relative soil moisture and precipitation, as well as potential evaporation in dry land were stronger than those in paddy fields, and the correlation between relative soil moisture and temperature in paddy fields was stronger than that in dry land. In winter, the correlations between relative soil moisture and precipitation in paddy 
fields and in dry land were relatively close. The correlation between relative soil moisture and potential evaporation in paddy field was stronger than that in dry land. The correlation between relative soil moisture and temperature in dry land was stronger than that in paddy fields. These suggested that the relative soil moisture in dry land in the northern agricultural region in summer and autumn was more affected by precipitation and evaporation. In winter, the influence of meteorological factors on relative soil moisture was weakened due to the formation of seasonal frozen soils in dry land of northern China, while relative soil moisture in Southwest Region, Middle and Lower Yangtze River Region, and South China Region was still affected by meteorological factors.

\section{Conclusions}

(1) Since 1993, the relative soil moisture of farmland in China has shown a fluctuant increasing trend.

(2) The relative soil moisture of farmland in China was generally greater than $60 \%$. The distribution area has been expanding northward and westward with the summer monsoon since mid-April and has been shrinking eastward and southward since late October. The relative soil moisture increased with the increase of soil depth, and the distribution area with a high relative soil moisture also increased with the increase of soil depth.

(3) The interannual tendency rate of relative soil moisture in farmland ranged from $-2.9 \% / \mathrm{a}$ to $5 \% / \mathrm{a}$, and the areas where the interannual tendency rate was positive and negative were interlacedly distributed, and the area with positive interannual tendency rate increased with the increase of soil depth. The interannual and intermonthly variation of relative soil moisture at each soil depth showed a fluctuant increasing trend. The relative soil moisture of farmland increased fastest in summer and autumn, and the variation range decreased with the increase of soil depth.

(4) The relative soil moisture was positively correlated with precipitation, negatively correlated with potential evaporation and temperature.

(5) The annual average relative soil moisture value in paddy fields was higher than that in dry land. The difference of annual average relative soil moisture in these two types of farmland increased with the increase of soil depth. The meteorological factors had a great influence on the relative soil moisture of dry land in spring, summer and autumn, and they had a greater impact on the relative soil moisture of paddy fields in winter.

\section{References}

Allen R G, Pruitt W O, Wright J L et al., 2006. A recommendation on standardized surface resistance for hourly calculation of reference ETo, by the FAO56 Penman-Monteith method. Agricultural Water Management, 81(1): $1-22$.

Baroni G, Ortuani B, Facchi A et al., 2013. The role of vegetation and soil properties on the spatio-temporal variability of the surface soil moisture in a maize-cropped field. Journal of Hydrology, 489(3): 148-159.

Chen S Y, Guo K Z, Dong A X, 2008. Research of variety rule of soil humidity in Loess Plateau of China. Plateau Meteorology, 27(3): 530-537. (in Chinese)

Cho E, Choi M, 2014. Regional scale spatio-temporal variability of soil moisture and its relationship with meteorological factors over the Korean Peninsula. Journal of Hydrology, 516(17): 317-329.

Delworth T L, Manabe S, 1988. The influence of potential evaporation on the variabilities of simulated soil wetness and climate. Journal of Climate, 1(5): 523-547.

Delworth T L, Manabe S, Stouffer R J, 1993. Interdecadal variations of the thermohaline circulation in a coupled ocean-atmosphere model. Journal of Climate, 6(11): 1993-2011.

Deng J Z, 1982. Some problems on the comprehensive agricultural regionalization of China. Geographical Re- 
search, 1(1): 9-18. (in Chinese)

Fang W S, Deng T H, Liu R H et al., 2005. Variation regularities of soil water in vari-type soils in Henan Province. Meteorological Science and Technology, 33(2): 182-184. (in Chinese)

Ju H R, Zhang Z X, Zhao X L et al., 2018. The changing patterns of cropland conversion to built-up land in China from 1987 to 2010. Journal of Geographical Sciences, 28(11): 1595-1610.

Li R C, Zhang X Z, Wang L H et al., 2011. Analysis on soil moisture content in the middle reaches of the Yellow River. Arid Zone Research, 28(1): 85-91. (in Chinese)

Lu D R, Huang B, Wang J S. 2011. Change of the ten-day precipitation and its relationship with soil moisture in the rain-fed area east of the Yellow River in Gansu Province. Agricultural Research in the Arid Areas, 29(2): 230-235. (in Chinese)

Ma Z G, Wei H L, Fu C B et al., 1999. Progress in the research on the relationship between soil moisture and climate change. Advance in Earth Sciences, (3): 88-94. (in Chinese)

Ma Z G, Wei H L, Fu C B et al., 2000. Relationship between regional soil moisture variation and climatic variability over east China. Acta Meteorologica Sinica, 58(3): 278-287. (in Chinese)

National Agricultural Regionalization Commission (NARC), 1981. Comprehensive Agricultural Regionalization of China. Beijing: China Agriculture Press. (in Chinese)

Wan G N, Yang M X, Wang X J et al., 2012. Variations in soil moisture at different time scales of BJ Site on the central Tibetan Plateau. Chinese Journal of Soil Science, 43(2): 286-293. (in Chinese)

Wang F Q, Wang L, Chen X, 2015. Analysis of relative soil moisture variation characteristics and influencing factors in Zhengzhou City. Water Saving Irrigation, (2): 8-11. (in Chinese)

Wang L, Wen J, Wei Z G et al., 2008. Soil moisture over the west of Northwest China and its response to climate. Plateau Meteorology, 27(6): 1257-1266. (in Chinese)

Wang S P, Zhang C J, Song L C et al., 2013. Relationship between soil relative humidity and the multiscale meteorological drought indexes. Journal of Glaciology \& Geocryology, 35(4): 865-873. (in Chinese)

Yamamoto J K, 2007. On unbiased backtransform of lognormal kriging estimates. Computational Geosciences, 11(3): 219-234.

Younis S M Z, Iqbal J, 2015. Estimation of soil moisture using multispectral and FTIR techniques. Egyptian Journal of Remote Sensing and Space Science, 18(2): 151-161.

Zhang J, Zhang W Y, Wang X Y et al., 2012. Changes characteristics of the soil moisture in semi-arid areas. Journal of Lanzhou University, 48(2): 57-61. (in Chinese)

Zhang J Y, Dong W J, Ye D Z et al., 2003. New evidence for effects of land cover in China on summer climate. Chinese Science Bulletin, 48(1): 91-95. (in Chinese)

Zhang L, Lü H Q, Wang L Y et al., 2016. Spatial-temporal characteristics of soil moisture in China. Acta Geographica Sinica, 71(9): 1494-1508. (in Chinese)

Zhang Q, Wang S, 2007. Study on annual water-heat characteristics and annual variation of surface radiation balance in arid desert area. Progress in Natural Science, 17(2): 211-216. (in Chinese)

Zhang R H, Liu L, Zuo Z Y, 2016. Variations of soil moisture over China and their influences on Chinese climate. Chinese Journal of Nature, 38(5): 313-319. (in Chinese)

Zhang W J, Zhou T J, Yu R C, 2008. Spatial distribution and temporal variation of soil moisture over China (Part I): Multi-data intercomparison. Chinese Journal of Atmospheric Sciences, 32(3): 581-597. (in Chinese)

Zhang X Z, Wu X Y, He J H, 2004. Vertical character of soil moisture in China. Acta Meteorologica Sinica, 62(1): 51-61. (in Chinese)

Zhang Y F, Wang X P, Pan Y X et al., 2011. The dependence of surface albedo on soil moisture in an arid desert area. Journal of Desert Research, 31(5): 1141-1148. (in Chinese)

Zhou B, Li J, Lin J J et al., 2015. Soil relative moisture characteristics and influencing factors in Liaoning province in spring. Chinese Journal of Ecology, 34(6): 1630-1637. (in Chinese)

Zhu G F, He Y Q, Pu T et al., 2011. Spatial distribution and temporal trends in potential evapotranspiration over Hengduan Mountains region from 1960 to 2009. Acta Geographica Sinica, 66(7): 905-916. (in Chinese)

Zhu G F, Qin D H, Tong H L et al., 2016. Variation of Thornthwaite moisture index in Hengduan Mountains, China. Chinese Geographical Science, 26(5): 687-702.

Zhu G F, Shi P J, Pu T et al., 2013. Changes of surface soil relative moisture content in Hengduan Mountains, China, during 1992-2010. Quaternary International, 298(7): 161-170.

Zhu H D, Shi Z H, Fang N F et al., 2014. Soil moisture response to environmental factors following precipitation events in a small catchment. Catena, 120(3): 73-80.

Zhu H J, Chen J F, Chen S L et al., 2010. Soil Geography. Beijing: Higher Education Press. (in Chinese)

Zhuo G, Chen T, Zhou K S et al., 2015. Spatial and temporal distribution of soil moisture over the Tibetan Plateau during 2009-2010. Journal of Glaciology \& Geocryology, 37(3): 625-634. (in Chinese)

Zuo Z Y, Zhang R H, 2007. The spring soil moisture and the summer rainfall in eastern China. Chinese Science Bulletin, 52(14): 1722-1724. (in Chinese)

Zuo Z Y, Zhang R H, 2018. Spatial and temporal variations of spring soil moisture in East China. Scientic Sinica Terrae, 38(11): 1428-1437. (in Chinese) 